\title{
Separation of mercury in industrial processes of Polish hard steam coals cleaning
}

\author{
Krzysztof Wierzchowski ${ }^{1, a}$, and Ireneusz Pyka ${ }^{1}$ \\ ${ }^{1}$ Glowny Instytut Gornictwa, 40-166 Katowice, Poland
}

\begin{abstract}
Coal use is regarded as one of main sources of anthropogenic propagation of mercury in the environment. The coal cleaning is listed among methods of the mercury emission reduction. The article concerns the statistical assessment of mercury separation between coal cleaning products. Two industrial processes employed in the Polish coal preparation plants are analysed: coal cleaning in heavy media vessels and coal cleaning in jigs. It was found that the arithmetic mean mercury content in coarse and medium coal size fractions for clean coal from heavy media vessels, amounts $68.9 \mu \mathrm{g} / \mathrm{kg}$, and most of the results lay below the mean value, while for rejects it amounts $95.5 \mu \mathrm{g} / \mathrm{kg}$. It means that it is for around $25 \mu \mathrm{g} / \mathrm{kg}$ greater than in the clean coal. The arithmetic mean mercury content in raw coal smalls amounts around $118 \mu \mathrm{g} / \mathrm{kg}$. The cleaning of smalls in jigs results in clean coal and steam coal blends characterized by mean mercury content $96.8 \mu \mathrm{g} / \mathrm{kg}$ and rejects with mean mercury content $184.5 \mu \mathrm{g} / \mathrm{kg}$.
\end{abstract}

\section{Introduction}

Coal use is regarded as one of main sources of anthropogenic propagation of mercury in the environment. [1-4]. Determination of the mercury content in raw coal and assessment of potential reduction of mercury in used coal have become the crucial topic for coal dependent economies. Coal cleaning is regarded as one of the methods of mercury in coal reduction. This method is so called precombustion [3-9]. Thus, coal cleaning, which reduces the ash in coal and increases the calorific value of the coal fuel, has gained additional significance.

The existing results of research have revealed that cleaning of Polish hard steam coal enables to reduce the mercury content in clean coal, in comparison with raw coal, by $18-79 \%$ [10-12]. More detailed research showed that the result of coal cleaning, in terms of the mercury content reduction, depended on technological characteristics of given coal and on the size fraction of cleaned coal [12]. By the technological characteristics we understand the distribution of ash, mercury and other coal quality parameters as a function of coal grains size and density. The coal cleaning processes were invented to increase the quality parameters of coal fuels, what was quantified first of all by ash reduction and increase of calorific value. The mercury reduction obtained in the coal cleaning processes can be treated as a supporting effect.

\footnotetext{
${ }^{\text {a }}$ Corresponding author: kwierzchowski@gig.eu
} 
The aim of this paper is a statistical assessment of mercury separation between coal cleaning products in industrial processes in the Polish hard steam coal preparation plants. Two coal cleaning processes and results of separation in industrial cleaning devices were analysed:

- coal cleaning of $+20 \mathrm{~mm}$ size fraction in dense media vessels to produce coarse and medium coal size grades (cobbles, nuts, pea coals)

- smalls cleaning in jigs.

The performed work concerned assessment of results of industrial cleaning devices without analyzing of the effectiveness of their performance. Additionally, in one location the variation of ash and mercury content in the feed (raw coal) and the clean coal was investigated.

\section{Material and methods}

In 2015 all coal size fractions produced in Polish collieries producing hard steam coal (excluding collieries belonging to Jastrzebska Spolka Weglowa S.A.) were sampled.

Gross samples of all coal size grades were collected from increments taken for from one to two weeks, depending on local conditions. The increments were taken at the same time with those sampled in routine sampling operations in all collieries under consideration. In the case of works concerning the variation of mercury in the feed and the clean coal from a jig, increments taken constituted the gross samples. This sampling lasted one month. One sample of the feed and one sample of the clean coal were taken per day. Sampling conformed to requirements of the following standards:

- hard coal and brown coal: methods of sampling and laboratory samples preparation PN90/G-04502

- hard coal and coke: mechanical sampling - Part 2: Coal - Sampling from moving streams PN-ISO 13909-2

- hard coal and coke: mechanical sampling - Part 3: Coal - Sampling from stationary lots PNISO 13909-3

- hard coal and coke: mechanical sampling - Part 4: Coal - Preparation of test samples PNISO 13909-4

- $\quad$ hard coal and coke: manual sampling PN-ISO 18283.

The ash and mercury contents were determined using the following standards and procedures:

- solid fuels: determination of ash by gravimetric method PN-80/G-04512 and PN 80/G$04512 \mathrm{Az} 1$

- the certified internal procedure, elaborated in Glowny Instytut Gornictwa No. SC-1.PB.23 applying the Cold-Vapor Atomic Absorption Spectrometry, using the analyzer MA-2000 of Nippon Instrument Corporation. It is a fully automated measurement system for determination of mercury content in solid materials, gases and liquids through sample combustion or evaporation.

In this article the results of determination of ash in coal are given in \% (air dried basis) and the mercury content is given in $\mu \mathrm{g} / \mathrm{kg}$ (air dried basis).

\section{Results}

The results of determination of mercury content in the cleaned coal and rejects products of cleaning of $+20 \mathrm{~mm}$ size fractions in heavy media vessels in 27 Polish coal preparation plants are illustrates in Fig. 1. The statistical distributions of mercury content in both groups of products (cleaned coals and rejects) are presented in Fig. 2 and 3. 


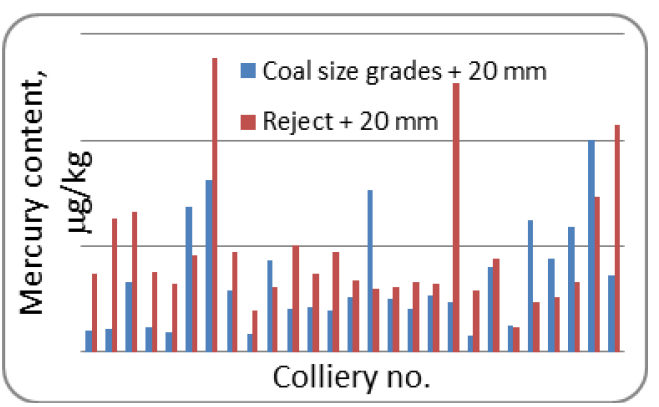

Figure 1. Mercury content in products (cleaned coal and rejects) of cleaning of $+20 \mathrm{~mm}$ size fractions in heavy media vessels in 27 Polish coal preparation plants.

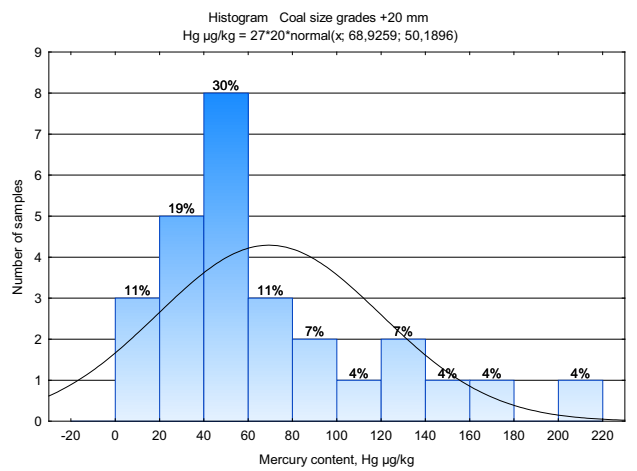

Figure 2. Distribution of mercury content in cleaned coals (coarse and medium coal size fractions - commercial products) from $+20 \mathrm{~mm}$ size fraction cleaning.

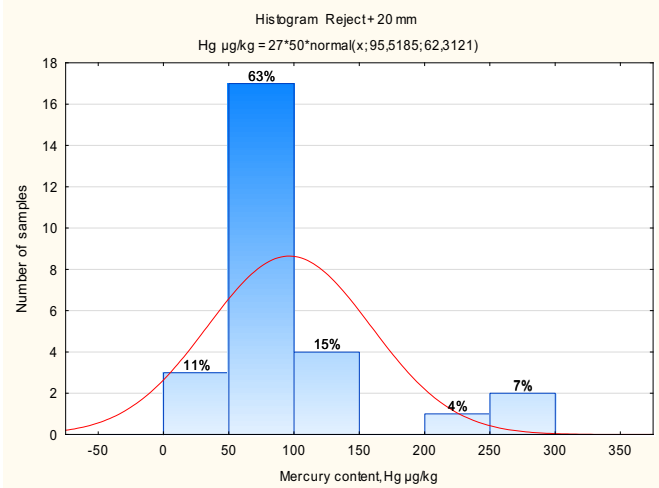

Figure 3. Distribution of mercury content in rejects from $+20 \mathrm{~mm}$ size fraction cleaning.

Figures 4, 5 and 6 illustrate distributions of the mercury content in raw smalls and the products of their cleaning in jigs in Polish coal preparation plants. The amounts of feeds and products are not equal to the number of coal preparation plants because in some cases two streams of smalls are treated and they could be analysed separately. The results of analyses of the variation in one month period of ash and mercury in raw smalls (feed) and cleaned coal from a jig are presented in Fig. 7 and 8. 


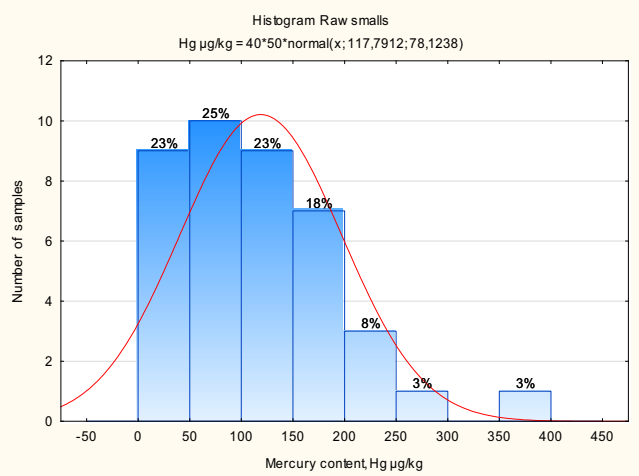

Figure 4. Distribution of mercury content in raw smalls.

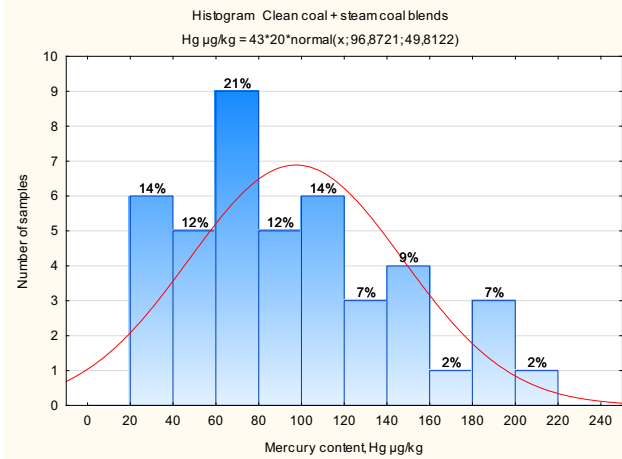

Figure 5. Distribution of mercury content in cleaned coals and steam coal blends.

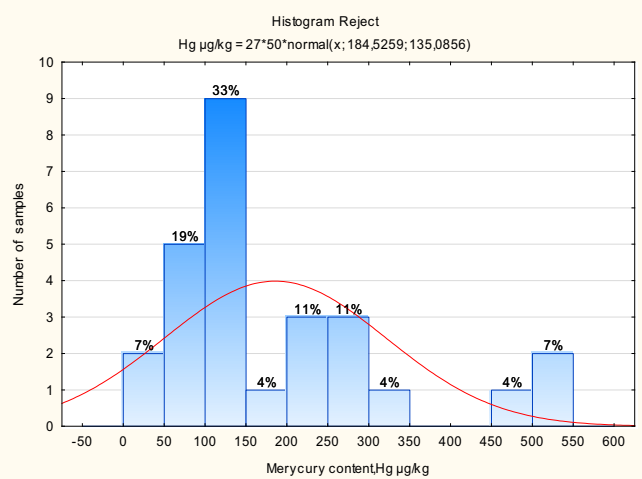

Figure 6. Distribution of mercury content in rejects from smalls cleaning. 


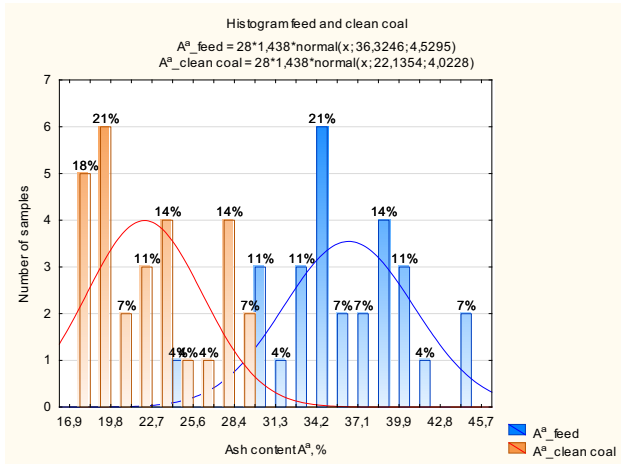

Figure 7. Variations of ash in raw smalls and the clean coal in one of Polish coal preparation plants.

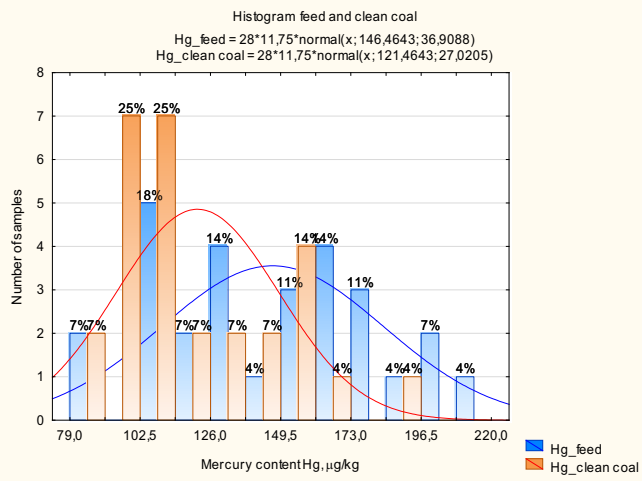

Figure 8. Variations of mercury in raw smalls and the clean coal in one of Polish coal preparation plants.

\section{Results and discussion}

The mercury content in coarse and medium coal size grades fits the broad interval: $20-220 \mu \mathrm{g} / \mathrm{kg}$. In the most cases mercury in cleaned coals is lower than in rejects from the same process (Fig. 1). In 7 cases only, mercury in cleaned coals is higher than in rejects form the same process. It illustrates differences in technological characteristics of coal cleaned in different coal preparation plants. The densities of heavy media in Polish coal preparation plants amount mainly $1.6-1.7 \mathrm{~g} / \mathrm{cm}^{3}$, although there are exceptions. In the first case mercury concentrates in fraction $+1.7 \mathrm{~g} / \mathrm{cm}^{3}$, while in the second case in the fraction $-1.7 \mathrm{~g} / \mathrm{cm}^{3}$. The arithmetic mean mercury content in coarse and medium coal size fractions amounts $68.9 \mu \mathrm{g} / \mathrm{kg}$ (Fig. 2). Most of the results lie below the mean value. The characteristic feature of this distribution is the "long tail" values greater than $100 \mu \mathrm{g} / \mathrm{kg}$. The arithmetic mean mercury content in rejects from the processes of $+20 \mathrm{~mm}$ size fraction cleaning amounts $95.5 \mu \mathrm{g} / \mathrm{kg}$ (Fig. 3). It means that it is more than $25 \mu \mathrm{g} / \mathrm{kg}$ greater than in clean coals. In the case of rejects the histogram is more concentrated around the mean value but it is also characterized by "the long tail". Three values exceed $200 \mu \mathrm{g} / \mathrm{kg}$. Taking into consideration that the yield of clean coals form the cleaning $+20 \mathrm{~mm}$ size fractions amounts $40-70 \%$ of the feed mass one can assess that the cleaning of $+20 \mathrm{~mm}$ coal size fraction in Polish coal preparation plants gives the medium reduction of mercury load in commercial products, in comparison to raw coal by around $50 \%$.

The mercury content in raw smalls fits also the broad interval: $20-400 \mu \mathrm{g} / \mathrm{kg}$, and the arithmetic mean value amounts $117.8 \mu \mathrm{g} / \mathrm{kg}$ (Fig. 4). The histogram is concentrated around the mean value but it 
is also characterized by "the long tail" and two values exceed $250 \mu \mathrm{g} / \mathrm{kg}$. From such raw smalls the commercial products from coal cleaning were obtained (clean coals and steam coal blends), for which the mercury distributions are illustrates in Fig. 5. The pure clean coal is sold as a commercial steam coal products only in a few cases, so the analyses are broaden by steam coal blends containing the clean coal. The analysis doesn't assess the whole potential of mercury reduction in processes of smalls cleaning. The mercury content in smalls, commercial products, fits less broad interval: 20 $220 \mu \mathrm{g} / \mathrm{kg}$, and the mean value amounts $96.8 \mu \mathrm{g} / \mathrm{kg}$. The mercury content in rejects from smalls cleaning fits extremely broad interval: $20-550 \mu \mathrm{g} / \mathrm{kg}$, and the mean value amounts $184.5 \mu \mathrm{g} / \mathrm{kg}$. Most of the results lie below the mean value but the distribution is characterized by the "long tail" In three cases the mercury content is greater than $450 \mu \mathrm{g} / \mathrm{kg}$.

Unfortunately, the variation of quality parameters of feeds to jigs is significant. Most of Polish coal preparation plants are not equipped in systems for feed quality stabilizing. Fig. 7 and 8 illustrate the statistical attempt to assess dependence of some clean coal quality parameters on the parameters of feed. Although, in the case of ash and mercury, for the whole population of results of one month lasting analyses, the mean values for clean coal are smaller than for raw coal (feed). A huge variation of both parameters can be observed. In the case of ash reduction is round $14 \%$ from $36.32 \%$ to $22.14 \%$, and in the case of mercury the reduction was around $25 \mu \mathrm{g} / \mathrm{kg}$, from $146 \mu \mathrm{g} / \mathrm{kg} \mathrm{do} 121 \mu \mathrm{g} / \mathrm{kg}$. It is rather impossible to obtain ash in clean coal greater than in raw coal, but in the case of mercury such situations are observed. The distributions of ash in the feed and in the clean coal are more concentrated around the mean values than in the case of the distributions of mercury in the feed and the clean coal. It can be concluded that variation of coal in terms of mercury content is greater than in terms of ash.

\section{Conclusions}

1. The arithmetic mean mercury content in coarse and medium coal size fractions from the processes of $+20 \mathrm{~mm}$ size fraction cleaning in Polish coal preparation plants amounted $68.9 \mu \mathrm{g} / \mathrm{kg}$ in 2015 . Most of the results lied below the mean value. The arithmetic mean mercury content in rejects amounted $95.5 \mu \mathrm{g} / \mathrm{kg}$, it means, it was more than $25 \mu \mathrm{g} / \mathrm{kg}$ greater than in clean coals.

2. The arithmetic mean mercury content in raw smalls in Polish coal preparation plants amounted $117.8 \mu \mathrm{g} / \mathrm{kg}$ in 2015. Smalls all commercial products composed using clean coal, were characterised by the medium mercury content $96.8 \mu \mathrm{g} / \mathrm{kg}$, while the mean mercury content in rejects from smalls cleaning amounted $184.5 \mu \mathrm{g} / \mathrm{kg}$.

3. Raw small are characterized by huge variation of quality parameters what had to influence the cleaning processes. The statistical analysis of performance of a jig in one of Polish coal preparation plans showed that despite of the fact that the medium mercury content in clean coal was smaller than in raw smalls (feed) in some cases (days) the instantaneous results of mercury determinations in the feed and clean product were inverse.

\section{Acknowledgements}

The results of the determination of mercury commercial products (coal size grades) of Polish hard coal collieries have been obtained in the project funded within the framework of the Applied Research Program of the Polish National Centre for Research and Development, entitled: The elaboration of a data base on mercury content in domestic coal, technological guidelines of further mercury reduction, including the defining of benchmarks for domestic indices of mercury emission" - acronym "Hg Base" ("Baza Hg"), (PBS2/A2/14/2013). 


\section{References}

1. UNEP Chemical Branch. The Global Atmospheric Mercury Assessment: Sources, Emissions and Transport (UNEP-Chemicals, Geneva, 2008)

2. A. Glodek, J.M. Pacyna, Atmos. Environ., 43, 5668 (2009)

3. B. Toole-O'Neil, S.J. Tewalt, R.B. Finkelman, D.J. Akers, Fuel Process. Technol., 78, 47 (1999)

4. J.H. Pavlish, E.A. Sondreal, M.D. Mann, E.S. Olson, K.C. Galbreath, D.L. Laudal, S.A. Benson, Fuel Process. Technol., 82, 89 (2003)

5. M. Mastalerz, A. Drobniak, Int. J. Coal Geol., 62, 223 (2005)

6. L.L. Sloss, IEA Clean Coal Centre Raport No. CCC/134 (London, UK, 2008)

7. L.L. Sloss, IEA Clean Coal Centre Raport No. CCC/195 (London, UK, 2012)

8. UNEP-United Nations Environmental Programme (DTIE, Geneva, Switzerland, 2010)

9. Ya.E. Yudovich, M.P. Ketris, Int. J. Coal Geol., 62, 135 (2005)

10. T. Dziok, A. Strugala, A. Rozwadowski, J. Gorecki, S. Ziomber, Energy Pol., 17(4), 277 (2014)

11. I. Pyka, K. Wierzchowski, Physicochem. Probl. Miner. Process. 52(1), 193 (2016)

12. I. Pyka K. Wierzchowski, Arch. Min. Sci., 55, 347 (2010) 